Chronic Obstructive Pulmonary Diseases: Journal of the COPD Foundation

\author{
Original Research
}

\title{
Exacerbations, Health Resource Utilization, and Costs Among Medicare Beneficiaries with Chronic Obstructive Pulmonary Disease Treated with Nebulized Arformoterol Following a Respiratory Event
}

Maryam Navaie, DrPH, MBA ${ }^{1,2}$ Bartolome R. Celli, $\mathrm{MD}^{3}$ Zhun Xu, $\mathrm{PhD}^{4}$ Soojin Cho-Reyes, $\mathrm{PhD}^{1}$ Carole Dembek, $\mathrm{MS}^{5}$ Todd P. Gilmer, $\mathrm{PhD}^{4}$

\section{Abstract}

Background: Long-acting beta2-agonists (LABAs), with or without inhaled corticosteroids (ICSs), delivered by handheld inhalers or nebulizers are recommended as maintenance therapy in chronic obstructive pulmonary disease (COPD). This study evaluated exacerbations, health resource utilization (HRU), and costs among Medicare beneficiaries with COPD on handheld ICS+LABA who switched to nebulized arformoterol (ARF) or continued ICS+LABA following a respiratory event.

Methods: Using Medicare claims, we identified beneficiaries with COPD (international classification of disease, 9th revision, clinical modification [ICD-9-CM] 490-492.xx, 494.xx, 496.xx) between 2010-2014 who had $\geq 1$ year of continuous enrollment in Parts $A, B$, and $D ; \geq 2$ COPD-related outpatient visits $\geq 30$ days apart or $\geq 1$ hospitalization(s); ICS+LABA use 90-days before ARF initiation; and a respiratory event (COPDrelated hospitalization or emergency department [ED] visit < 30 days before ARF initiation). Using propensity scores, 423 beneficiaries who switched to ARF were matched to 423 beneficiaries who continued on handheld ICS+LABA (controls). Difference-in-difference regression models examined outcomes at 180-days follow-up. Results: Beneficiaries who switched to ARF had 1.5 fewer exacerbations ( $p=0.015)$ but no difference in hospitalizations and ED visits compared to controls. Durable medical equipment (DME) costs were higher among ARF users than controls (\$1590), yet total health care costs were similar due to cost offsets by ARF in pharmacy (-\$794), inpatient (-\$524), and outpatient care (-\$65). ARF accounted for 55\% (\$886.63) of DME costs, with the remaining costs attributed to oxygen therapy (\$428.10) and nebulized corticosteroids (\$590.85). Conclusions: Switching from handheld ICS+LABA to nebulized ARF resulted in fewer COPD exacerbations among Medicare beneficiaries. Nebulized LABAs may improve outcomes in selected patients with COPD.

\footnotetext{
Abbreviations: long-acting beta2-agonist, LABA; inhaled corticosteroid, ICS; chronic obstructive pulmonary disease, COPD; health resource utilization, HRU; arformoterol, ARF; international classification of disease, 9th revision, clinical modification, ICD-9-CM; emergency department, ED; durable medical equipment, DME; long-acting muscarinic antagonist, LAMA; Centers for Medicare and Medicaid Services, CMS; chronic illness and disability payment system, CDPS; short-acting muscarinic antagonist, SAMA; short-acting beta2-agonist, SABA; systemic corticosteroids, CS; phosphodiesterase inhibitors, PDE4; difference-in-difference, DID; short-acting bronchodilators, SABDs; hospital readmission reduction program, HRRP

Funding Support: Sunovion Pharmaceuticals Inc.

Date of Acceptance: June 14, 2019

Citation: Navaie M, Celli BR, Xu Z, Cho-Reyes S, Dembek C, Gilmer TP. Exacerbations, health resource utilization, and costs among Medicare beneficiaries with chronic obstructive pulmonary disease treated with nebulized arformoterol following a respiratory event. Chronic Obstr Pulm Dis. 2019;6(4):297-307. doi: https://doi.org/10.15326/jcopdf.6.4.2019.0127
} 


\begin{tabular}{l}
\hline Advance Health Solutions, New York, New York \\
\hline 2 School of Professional Studies, Columbia University, New York, \\
New York \\
3 Harvard Medical School and Chronic Obstructive Pulmonary \\
Disease Center, Brigham and Women's Hospital, Boston, \\
Massachusetts \\
4 Department of Family Medicine and Public Health, Division of \\
Health Policy, University of California San Diego, La Jolla \\
\hline
\end{tabular}

5 Sunovion Pharmaceuticals Inc., Marlborough, Massachusetts

\section{Address correspondence to:}

Maryam Navaie, DrPH, MBA

Advance Health Solutions, LLC

5 Penn Plaza, 23rd Floor

New York, NY 10001

Phone : (212) 835-1510

E-mail: mnavaie@advancehealthsolutions.com

\section{Keywords:}

chronic obstructive pulmonary disease; Medicare; long-acting beta2-agonists; arformoterol; nebulized therapy; exacerbations; hospitalization; health resource utilization; costs; durable medical equipment

Note: An earlier version of this study was presented, in part, at the American Thoracic Society International Conference May 18-23, 2018 in San Diego, California.

\section{Introduction}

Chronic obstructive pulmonary disease (COPD) remains a public health challenge in the United States. ${ }^{1,2}$ The condition affects an estimated 16 million U.S. adults ${ }^{3}$ and is a leading cause of mortality. ${ }^{1,3}$ The natural progression of COPD is often aggravated by exacerbations which lead to an increase in health resource utilization (HRU), a reduction in healthrelated quality of life, a higher risk of mortality, and a greater cost burden. ${ }^{1,4,5}$ Thus, reducing the risk and severity of exacerbations is a key goal in the clinical management of COPD. ${ }^{6}$

Long-acting bronchodilators including long-acting beta2-agonists (LABAs), long-acting muscarinic antagonists (LAMAs), or LABA/LAMA combinations with or without inhaled corticosteroids (ICSs) are recommended as maintenance treatment for COPD. ${ }^{6}$ These therapeutic options can be administered by various devices including handheld inhalers and nebulizers. Across all patients with COPD in the United States, handheld ICS+LABA is the most commonly prescribed maintenance therapy. ${ }^{7-10}$ Among Medicare beneficiaries with COPD, nearly half are treated with ICS+LABA combination therapy. ${ }^{11}$

Individualized treatment approaches in COPD include assessing patient preferences and abilities to correctly use the inhalation device. ${ }^{12-15}$ Handheld inhalers are the most frequently used inhalation devices to administer COPD pharmacotherapies. ${ }^{16}$ However, for patients on handheld devices with poorly controlled COPD symptoms, nebulized maintenance treatment may be a more suitable choice. ${ }^{6}$ Indeed, past research has shown that some patients prefer using nebulizers. ${ }^{15}$

Whether patients with COPD on handheld ICS+LABA inhalers with a history of exacerbations can benefit from switching to a nebulized maintenance treatment remains unclear. Addressing this dearth of evidence could lead to valuable insights to potentially improve care delivery and yield cost savings, especially for the Medicare program given that $12 \%$ of Medicare beneficiaries are diagnosed with $\mathrm{COPD}^{17}$ and $69 \%$ of all hospitalized beneficiaries have COPD. ${ }^{18}$ The purpose of this retrospective study was to evaluate exacerbations, HRU, and costs among Medicare beneficiaries with COPD on handheld ICS+LABA therapy who switched to nebulized arformoterol (ARF) or continued to use handheld ICS+LABA following a respiratory event.

\section{Methods}

\section{Data Source}

This retrospective study used 100\% fee-for-service Medicare administrative data from the Centers for Medicare and Medicaid Services' (CMS) Chronic Condition Warehouse. The data included inpatient, outpatient, prescription (Part D), and long-term care claims from 2010 to 2014. The study was approved by the Institutional Review Board of the University of California San Diego and was subject to a CMS data use agreement.

\section{Cohort Selection and Study Design}

Medicare beneficiaries diagnosed with COPD (i.e., International Classification of Disease, 9th Revision, Clinical Modification [ICD-9-CM] codes 490.xx, 492. $\mathrm{xx}, 494 . \mathrm{xx}, 496 . \mathrm{xx}$ ) who had continuous enrollment in Parts A, B and D for a full year were identified $(\mathrm{N}=676,924)$. A total of 2412 beneficiaries met additional inclusion and exclusion criteria (Figure 1). 


\section{Figure 1. Flow Chart Depicting Selection of Study Population}

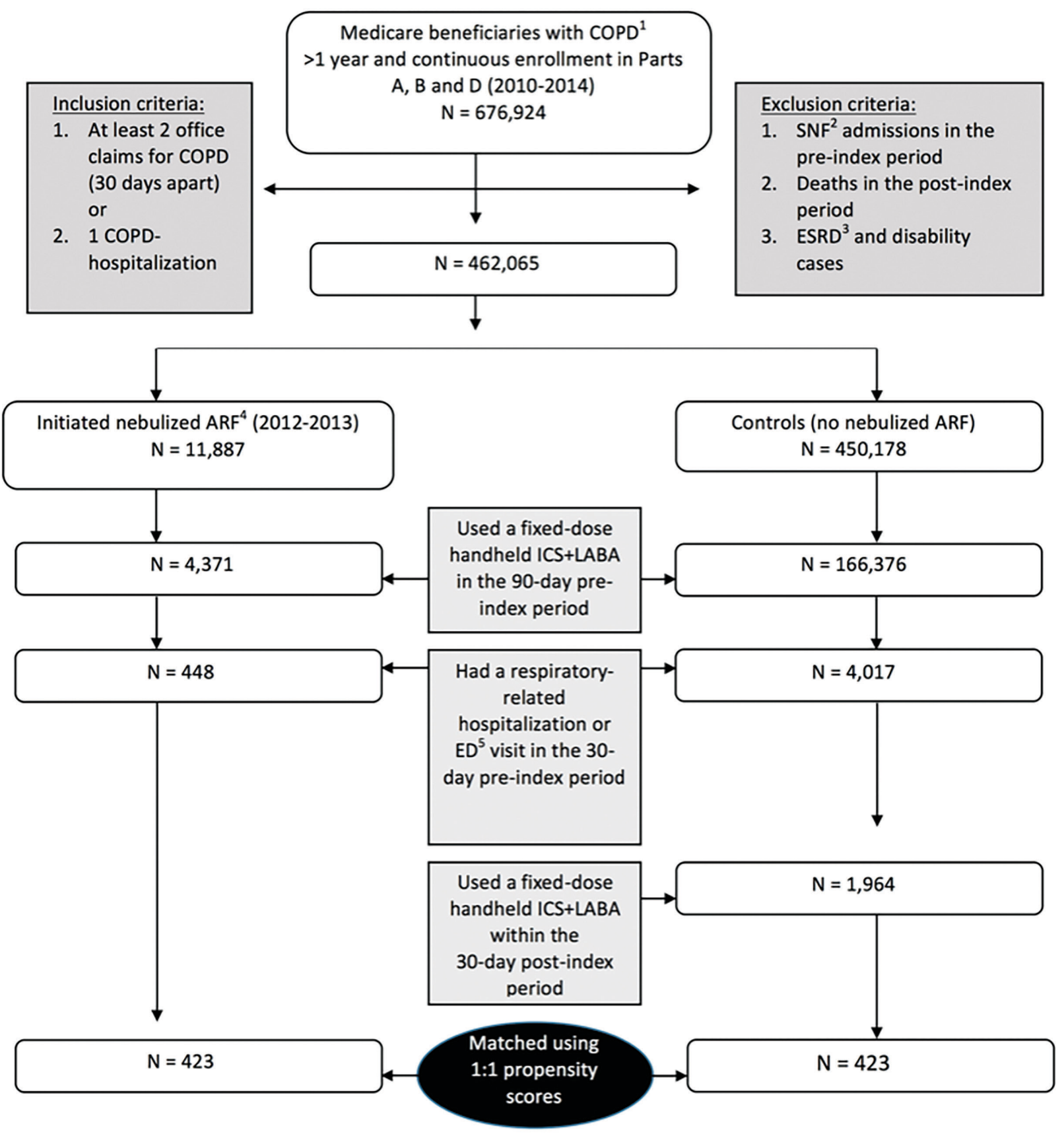

${ }^{1} \mathrm{COPD}=$ chronic obstructive pulmonary disease; ${ }^{2} \mathrm{SNF}=$ skilled nursing facility; ${ }^{3} \mathrm{ESRD}=$ end stage renal disease; ${ }^{4} \mathrm{ARF}=$ arformoterol; ${ }^{5} \mathrm{ED}=$ emergency department

Among these beneficiaries, 448 initiated nebulized ARF (cases) and 1964 received a fixed-dose ICS+LABA (controls) including fluticasone/salmeterol (Advair), budesonide/formoterol (Symbicort), or mometasone/ formoterol (Dulera) using a handheld inhaler. After performing 1:1 propensity score matching using the nearest neighbor without replacement, 423 beneficiaries were identified in each group. Matching covariates included sociodemographic characteristics, comorbidities, COPD treatment, and HRU in the preindex period.

To evaluate the effects of switching from a fixed-dose 


\section{Figure 2. Study Design}

Baseline Period (Pre-Index)
Treatment Follow-up Period (Post-Index)

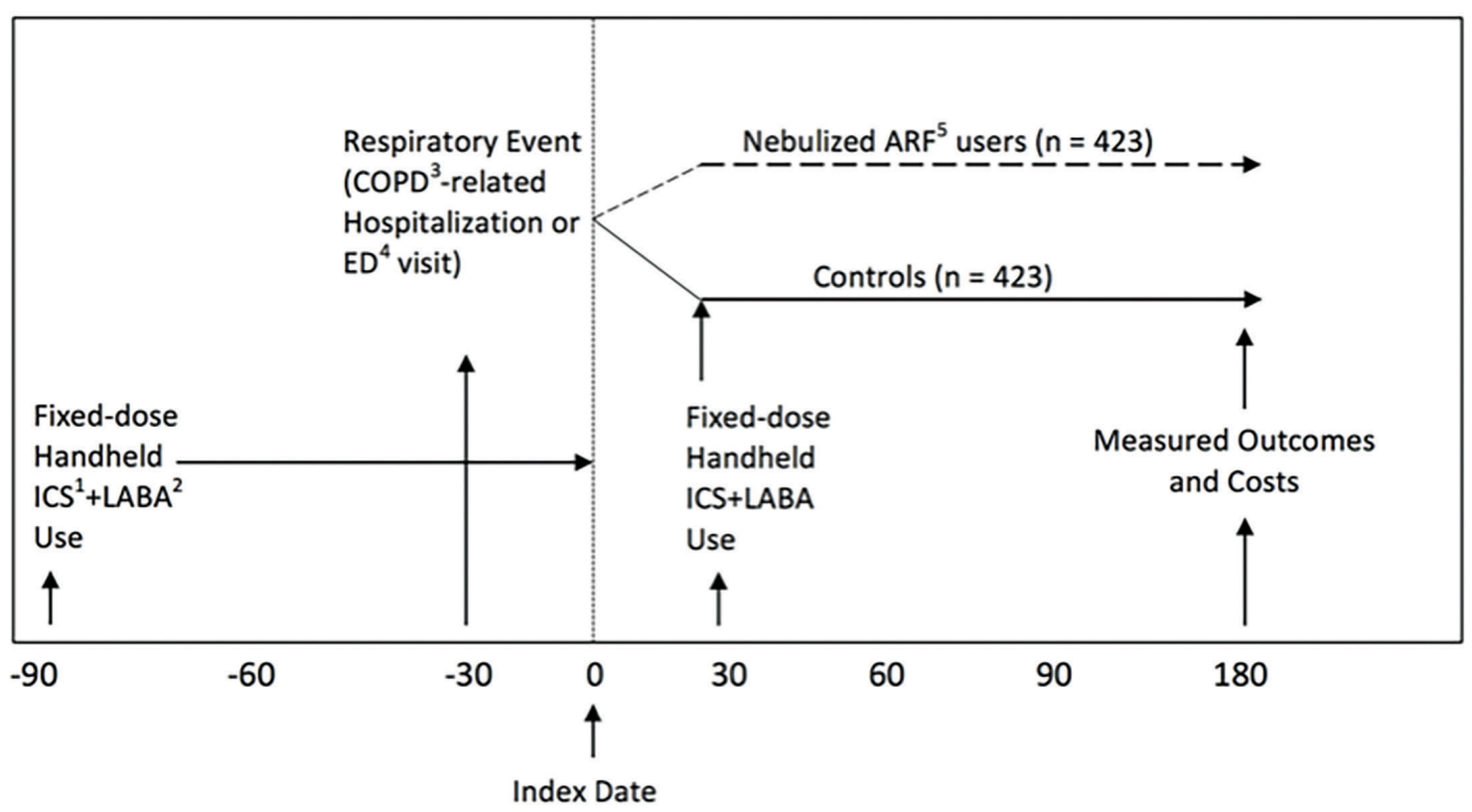

Time (Days)

${ }^{1} \mathrm{ICS}=$ inhaled corticosteroids; ${ }^{2} \mathrm{LABA}=$ long-acting beta2-agonists; ${ }^{3} \mathrm{COPD}=\mathrm{chronic}$ obstructive pulmonary disease;

${ }^{4} \mathrm{ED}=$ emergency department; ${ }^{5} \mathrm{ARF}=$ arformoterol

handheld ICS+LABA to nebulized ARF, beneficiaries were retrospectively assessed for a 9-month period that included 2 segments: (a) a 90-day pre-index (baseline) period, and (b) a 180-day post-index or treatment follow-up period (Figure 2). During the pre-index period, all beneficiaries were being treated with a fixed-dose handheld ICS+LABA therapy and no nebulized ARF. The index date was the date of first prescription for nebulized ARF between January 1, 2012 and December 31, 2013 for beneficiaries who were on fixed-dose handheld ICS+LABA who switched to ARF after resolution of a respiratory event, defined as a COPD-related hospitalization or an emergency department (ED) visit < 30 days before ARF initiation. Beneficiaries in the control group continued to receive a fixed-dose handheld ICS+LABA, as ascertained by prescription claims within 30 days after the index date. The index date for controls was randomly assigned to correspond to the date of nebulized ARF initiation in the treatment group. All outcomes were measured at 180-days post-index.

\section{Independent and Outcome Measures}

The following independent measures were examined: (a) demographic characteristics including age, sex, race, and regional residence; (b) dual-eligibility status (i.e., Medicare and Medicaid beneficiary); (c) comorbid conditions as measured by the Chronic Illness and Disability Payment System (CDPS) diagnostic classification ${ }^{19}$; (d) COPD treatments including shortacting muscarinic antagonists (SAMAs), LAMAs, short-acting beta2-agonists (SABAs), LABAs, ICSs, systemic corticosteroids (CSs), methylxanthines, phosphodiesterase inhibitors (PDE4), non-specific PDE inhibitors, mucolytics, and antibiotics; and (e) oxygen therapy.

Outcomes measures included: (a) the frequency of exacerbations, defined by an ED visit or a hospitalization for acute exacerbation of COPD (ICD-9-CM 491.21 or 491.22); (b) HRU including pharmacy, durable medical equipment (DME) use, hospitalizations (COPD-related and all-cause), outpatient care, ED visits, skilled nursing facility use, and home health care visits; and (c) costs. 


\section{Statistical Analysis}

To ensure balance in matching procedure, pairs were checked against caliper of one fifth of propensity score standard deviation and restricted to common support. Standardized differences for covariates were also calculated before and after matching. Descriptive statistics including means, standard errors, and frequencies were used to compare sociodemographic characteristics, COPD treatment, exacerbation frequency, and HRU between nebulized ARF users and controls. Differences in HRU outcomes between beneficiaries treated with nebulized ARF and controls were estimated using difference-in-difference (DID) regression models. DID estimates for count variables (e.g., number of exacerbations) were calculated using a zero-inflated negative binomial regression model. DID estimates for costs were analyzed using generalized linear regression with a gamma distribution. $P<.05$ denoted statistical significance. All analyses were performed with SAS Enterprise Guide 7.1.

\section{Results}

\section{Baseline Characteristics}

Beneficiaries treated with nebulized ARF were well matched to controls on sociodemographic and treatment characteristics (Table 1). The majority of beneficiaries were 70 years of age or older, female, non-Hispanic white, and from the South or Midwest regions of the United States. A higher proportion of beneficiaries in the control group were dual-eligible as compared to beneficiaries treated with nebulized ARF ( $54.4 \%$ versus $49.9 \%$, respectively).

In addition to receiving handheld ICS+LABA therapy, more than half of the beneficiaries in both groups were receiving oxygen therapy, > 60\% were on inhaled short-acting bronchodilators (SABDs) or antibiotics, and $50 \%$ were being treated with a LAMA (Table 1). About one-third of all beneficiaries were receiving a nebulized SABA.

\section{Exacerbations, Health-Related Utilization and Costs}

Beneficiaries treated with nebulized ARF had, on average, 1.5 fewer exacerbations at 180 days compared to controls ( $p=.015)$ (Figure 3 ). The probabilities of all-cause and COPD-related hospitalizations and ED visits were similar between the 2 groups (Figure 4).

At 180-days follow-up, health care costs for inpatient

\section{Table 1. Baseline Sociodemographic and Treatment Characteristics of Study Population}

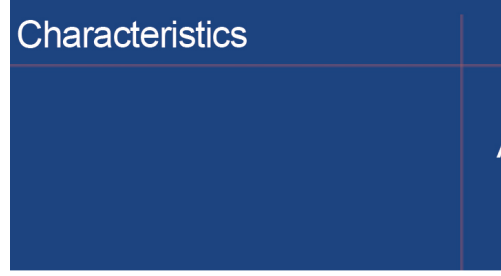

Medicare Beneficiaries

ARF Users

$(\mathrm{N}=423)$

$\mathrm{N}(\%)$
Nebulized Controls

\begin{tabular}{l|r|r}
\begin{tabular}{l} 
Age (years) \\
\hline$<65$
\end{tabular} & $104(24.6)$ & $106(25.0)$ \\
\hline 65 to 69 & $77(18.2)$ & $80(18.9)$ \\
\hline 70 to 74 & $97(22.9)$ & $87(20.6)$ \\
\hline 75 to 79 & $78(18.4)$ & $76(18.0)$ \\
\hline$\geq 80$ & $67(15.8)$ & $74(17.5)$ \\
\hline Race & \multicolumn{2}{|l}{} \\
\hline Non-Hispanic White & $385(91.0)$ & $376(88.9)$ \\
\hline Hispanic & $<11^{\mathrm{a}}$ & $12(2.8)$ \\
\hline African-American & $21(5.0)$ & $23(5.4)$ \\
\hline Other & $<11^{\mathrm{a}}$ & $<11^{\mathrm{a}}$ \\
\hline Female & $275(65.0)$ & $271(64.1)$ \\
\hline Dual-eligible & $211(49.9)$ & $230(54.4)$ \\
\hline Region & \multicolumn{2}{|}{} \\
\hline Midwest & $147(34.8)$ & $149(35.2)$ \\
\hline Northeast & $58(13.7)$ & $55(13.0)$ \\
\hline South & $177(41.8)$ & $172(40.7)$ \\
\hline West & $41(9.7)$ & $47(11.1)$ \\
\hline
\end{tabular}

\begin{tabular}{l|r|r}
\hline \multicolumn{3}{l}{ Pre-Index Period Diagnostics and Treatment } \\
\hline Spirometry Tests & $39(9.2)$ & $34(8.0)$ \\
\hline Oxygen & $216(51.1)$ & $225(53.2)$ \\
\hline Systemic CS & $355(83.9)$ & $356(84.2)$ \\
\hline Inhaled SABD & $265(62.7)$ & $272(64.3)$ \\
\hline Antibiotics & $254(60.1)$ & $265(62.7)$ \\
\hline LAMA & $213(50.4)$ & $213(50.4)$ \\
\hline Nebulized SABA & $133(31.4)$ & $124(29.3)$ \\
\hline Nebulized CS & $44(10.4)$ & $<11^{\mathrm{a}}$ \\
\hline Methylxanthines & $41(9.7)$ & $46(10.9)$ \\
\hline SAMA & $41(9.7)$ & $43(10.2)$ \\
\hline Inhaled CS & $15(3.6)$ & $15(3.6)$ \\
\hline Inhaled LABA & $<11^{\mathrm{a}}$ & $<11^{\mathrm{a}}$ \\
\hline
\end{tabular}

${ }^{a}$ cell blinded due to small sample size per CMS policy

$\mathrm{ARF}=$ arformoterol; $\mathrm{CS}=$ corticosteroids; $\mathrm{SABD}=$ short-acting bronchodilators; LAMA=long-acting muscarinic antagonists; SABA=short-acting beta2-agonists; LABA=long-acting beta2-agonists

care (-\$524 \pm 1303$)$, outpatient office visits (-\$65 \pm $352)$, and pharmacy $(-\$ 794 \pm 250)$ were lower for the nebulized ARF users but not significantly different from 


\section{Figure 3. Changes in the Number of Exacerbations at 180-Days Follow-Up Between Matched Medicare Beneficiaries Treated With Nebulized Arformoterol and Controls}

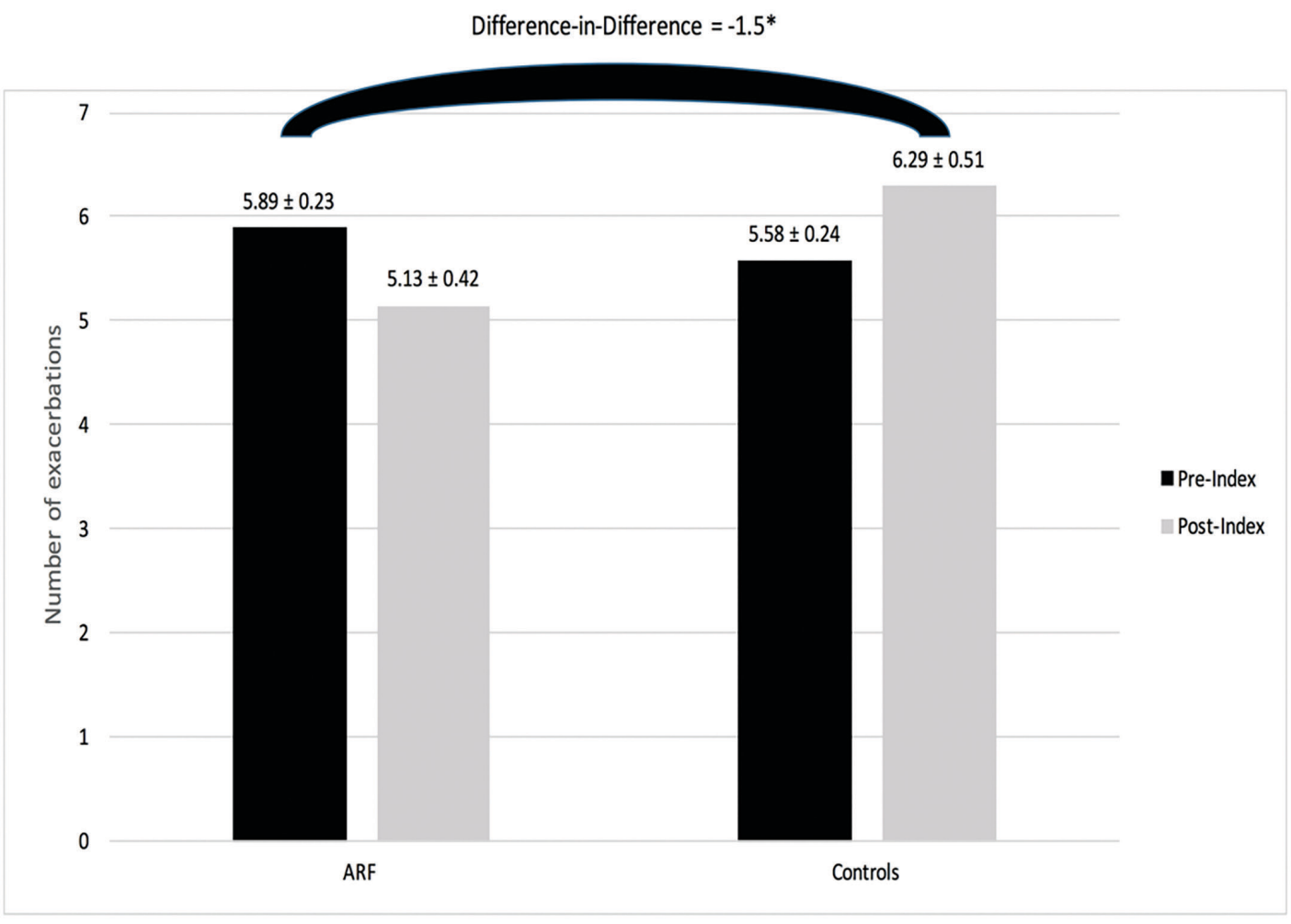

$\mathrm{ARF}=$ arformoterol; * $p=0.015$

controls (Figure 5). By contrast, home health care costs were slightly higher for nebulized ARF users relative to controls ( $\$ 66 \pm 138$ ), although the difference was not statistically different. On average, DME costs were significantly higher for beneficiaries on nebulized ARF $(\$ 1590 \pm 82)$ relative to controls $(p<.001)$. Further analysis of DME cost contributors revealed that nebulized ARF accounted for about 55\% (\$886.63) of the costs, with the remaining costs attributable to oxygen therapy (\$428.10) and nebulized CS (\$590.85) (Table 2). No significant differences in total costs were observed between the 2 groups.

\section{Discussion}

To our knowledge, our retrospective analysis is the first large study to compare exacerbations, HRU, and costs between Medicare beneficiaries with COPD who were treated with ICS+LABA and either switched to nebulized ARF or continued using handheld ICS+LABA following a respiratory event that included a COPD-related hospitalization or an ED visit $\leq 30$ days before ARF initiation. We found that beneficiaries who switched to nebulized ARF had 1.5 fewer exacerbations at 180-days follow-up than those who continued treatment with handheld ICS+LABA at similar total health care costs.

In a previous retrospective cohort study conducted in a small sample of 23 Medicare beneficiaries with uncontrolled COPD symptoms despite regular use of handheld ICS+LABA, researchers examined the effects of switching the medication delivery system to a nebulized formulation of ARF+CS (budesonide). ${ }^{20}$ They found a significant decrease in combined ED visits and hospitalizations stemming from reduced exacerbations after beneficiaries switched to nebulized ARF+CS when compared to beneficiaries who continued handheld ICS+LABA (0.22 versus 0.99, respectively, $p=0.002$ ). The study concluded that patients with severe COPD who are not achieving symptom control with a handheld ICS+LABA may 


\section{Figure 4. Changes in Health Resource Utilization at 180-Days Follow-Up Between Matched Medicare Beneficiaries Treated with Nebulized Arformoterol and Controls}

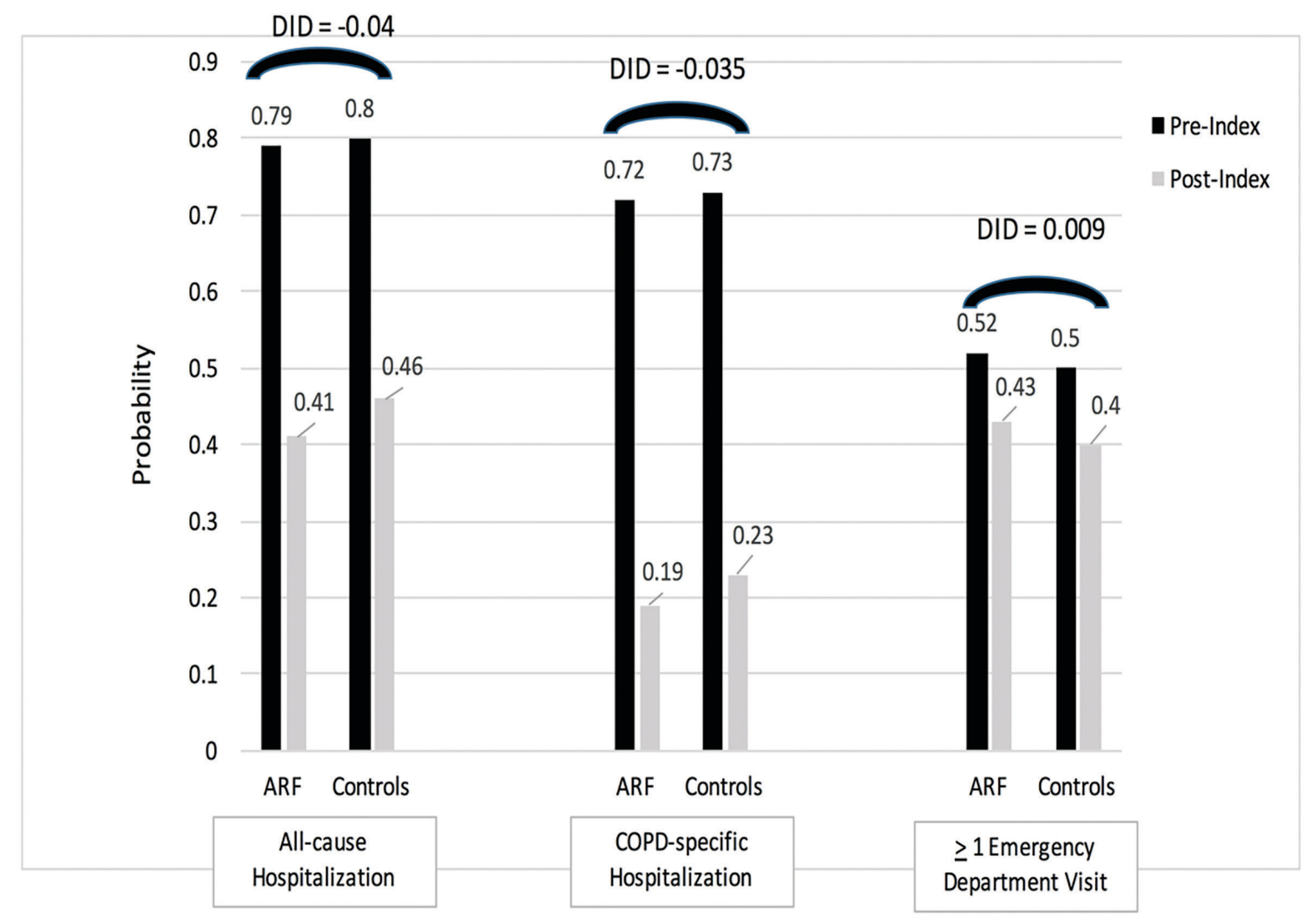

All standard errors were negligible (not shown)

$\mathrm{ARF}=$ arformoterol; DID=difference-in-difference

benefit from switching to the same medication using a nebulized delivery system.

Our study expands the current knowledge base stemming from previous research by showing that, despite higher DME costs among nebulized ARF users compared to controls, the total health care costs were similar between the 2 groups due to cost offsets by ARF in lower pharmacy, inpatient, and outpatient care. Moreover, we determined that nebulized ARF accounted for only 55\% of DME costs. Although previous studies among Medicare beneficiaries have shown that the use of maintenance medications (including handheld inhalers and nebulized therapies) lowers annual expenditures, ${ }^{21,22}$ we cannot directly compare our findings with these studies since we did not have a treatment naïve control group. Nonetheless, our results are consistent with past studies in suggesting that clinical decisions regarding the choice of maintenance therapies and delivery systems can impact COPD outcomes and costs. ${ }^{23,24}$

Preventing COPD exacerbations and repeat hospitalizations has become a key imperative in Medicare populations in light of the Medicare's Hospital Readmission Reduction Program (HRRP) which imposes reimbursement penalties for unplanned readmissions. ${ }^{25,26}$ As such, researchers have explored the potential factors associated with recurrent exacerbations among Medicare beneficiaries. Poor adherence to inhaled treatment regimens has been proposed as one of the key drivers of unplanned readmissions. ${ }^{11,27}$ The reasons for suboptimal adherence among patients with COPD are multifactorial. ${ }^{28,29}$ One contributing reason is that some patients with COPD have difficulty using inhaler devices properly. ${ }^{11,30-35}$ In real-world settings, proper use of handheld inhalers requires patients to have 
Figure 5. Difference-in-Difference in Costs at 180-Days Follow-Up Between Matched Medicare Beneficiaries Treated With Nebulized Arformoterol and Controls.

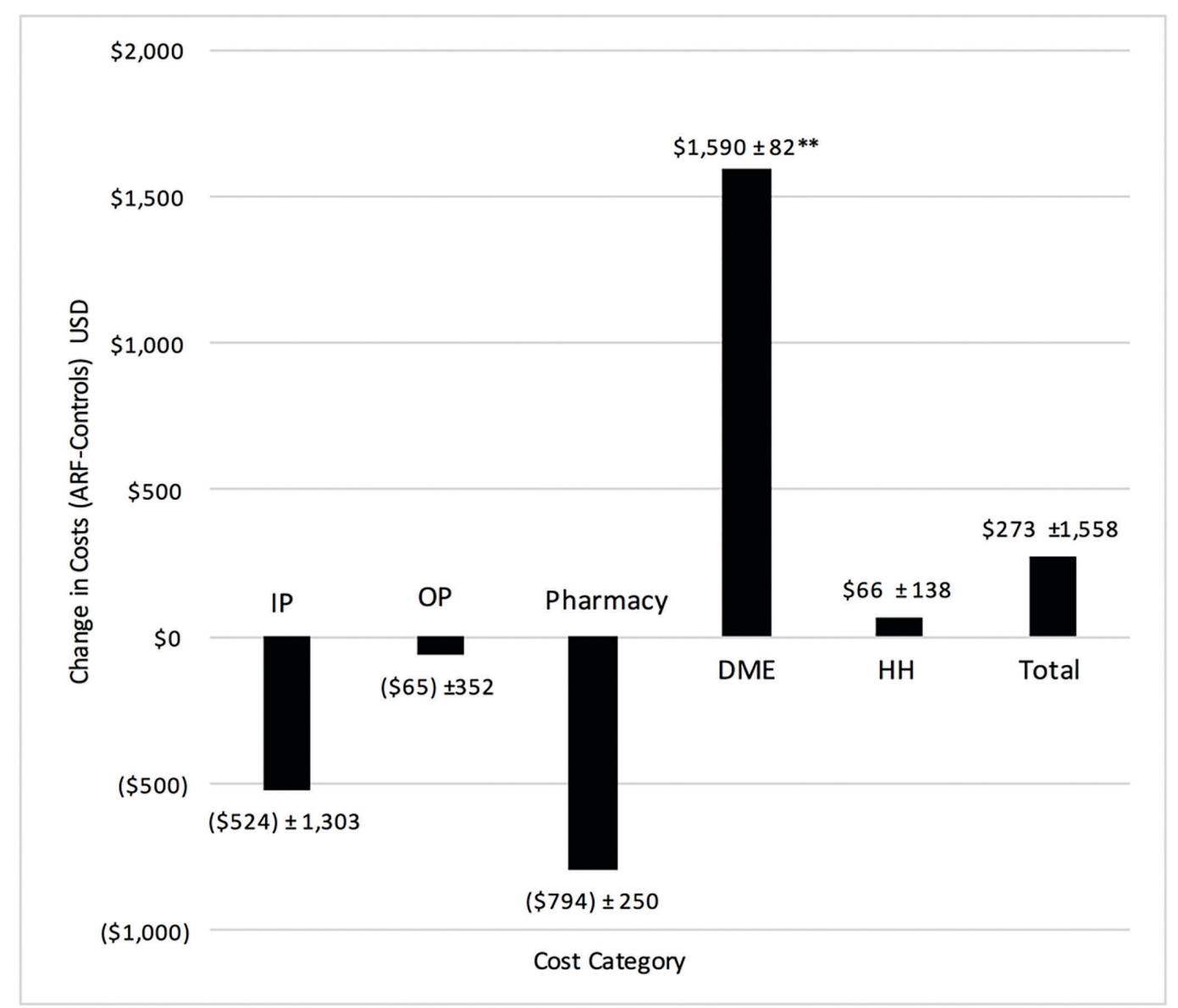

$\mathrm{IP}=$ inpatient including skilled nursing facility; OP=outpatient; DME=durable medical equipment; $\mathrm{HH}=$ home healthcare; ${ }^{* *} p<.0001$

\section{Table 2. Durable Medical Equipment Costs at 180-Days Follow-Up Between Matched Medicare Beneficiaries Treated with Nebulized Arformoterol and Controls}

\begin{tabular}{|c|c|c|c|c|c|c|}
\hline \multirow[b]{2}{*}{ Treatment } & \multicolumn{3}{|c|}{ Nebulized ARF Users $(\mathrm{N}=423)$} & \multicolumn{3}{|c|}{ Controls $(\mathrm{N}=423)$} \\
\hline & $\begin{array}{l}\text { Claims } \\
\text { (N) }\end{array}$ & $\begin{array}{c}\text { Beneficiaries } \\
(\mathrm{N})\end{array}$ & $\begin{array}{c}\text { DME } \\
\text { Payment }\end{array}$ & $\begin{array}{l}\text { Claims } \\
(\mathrm{N})\end{array}$ & $\begin{array}{c}\text { Beneficiaries } \\
(\mathrm{N})\end{array}$ & $\begin{array}{c}\text { DME } \\
\text { Payment }\end{array}$ \\
\hline Nebulized ARF & 1563 & 408 & $\$ 886.63$ & & & \\
\hline Nebulized SABA & 1099 & 260 & $\$ 25.28$ & 966 & 228 & $\$ 32.79$ \\
\hline Nebulized CS & 1085 & 265 & $\$ 590.85$ & 30 & $<11^{\mathrm{a}}$ & $\$ 15.78$ \\
\hline Oxygen & 2271 & 276 & $\$ 428.10$ & 2047 & 249 & $\$ 382.49$ \\
\hline
\end{tabular}

${ }^{\mathrm{a}}$ cell blinded due to small sample size.

$\mathrm{ARF}=$ arformoterol; $\mathrm{SABA}=$ short-acting beta2-agonists; $\mathrm{CS}=$ corticosteroids

hand-breath coordination, intact cognitive abilities to operate devices, the ability to hold their breath for up to 10 seconds, and the ability to generate adequate inspiratory force. ${ }^{13}$ Since these types of requirements 
can lead patients to stop inhaled therapy due to the perceived complexity of using handheld devices, ${ }^{36}$ the importance of matching the right inhalation device to the right patient cannot be over emphasized. Ultimately, prescribing a device that patients are unable to use properly can result in inadequate medication dose delivery which subsequently leads to more exacerbations, costly ED visits and hospitalizations. $6,27-32,37$

Our study had certain limitations inherent to retrospective observational studies that rely on administrative claims data including coding accuracy, missing or omitted data, and other indicators of reliability and validity associated with data quality. We did not have information on unobserved factors that may have potentially influenced medication management decisions such as the patient's cognitive impairment, hand-breath coordination abilities, dexterity, inhalation device preferences, or medication adherence. ${ }^{15,27,28,31,38,39}$ There was also no available data on factors related to the risk of exacerbations such as physical activity ${ }^{40}$ and lung function as a direct measure of COPD disease severity. ${ }^{6}$ Finally, our analysis was based on fee-for-service Medicare beneficiaries and may not be generalizable to managed Medicare or other COPD populations. Despite these limitations, our study included a large number of Medicare beneficiaries, careful propensityscore matching between nebulized ARF users and controls, and a comprehensive evaluation of health and economic outcomes.

\section{Conclusions}

Nebulized ARF may be an appropriate treatment option among patients with COPD following a respiratory event such as a COPD-related hospitalization or an ED visit. In our retrospective study, Medicare beneficiaries who switched to nebulized ARF for maintenance therapy after experiencing multiple respiratory events had a significant reduction in the number of exacerbations at 180 -days follow-up at similar overall costs when compared to beneficiaries who were treated on handheld ICS+LABA therapy. Selecting an inhalation device device that best matches the patient's clinical needs and his or her ability to use it successfully can increase the probability of positive outcomes.

\section{Acknowledgments}

We thank Vaidyanathan Ganapathy, PhD, formerly of Sunovion Pharmaceuticals Inc., for his support with study conceptualization and implementation. Authors' contributions were as follows: MN, SC, and $C D$ conducted literature searches and/or reviewed relevant articles identified through the searches; MN, BRC, SC, ZX, and TPG were responsible for study conceptualization, research design, and analytic plan development; ZX and TPG led data curation and analysis; and all authors were involved in results interpretation and presentation as well as preparation, review and final approval of the manuscript. An earlier version of this study was presented, in part, at the American Thoracic Society International Conference, May 18-23, 2018, in San Diego, California.

\section{Declaration of Interest}

$\mathrm{MN}$ and SC are employed by Advance Health Solutions, LLC which received funding from Sunovion Pharmaceuticals Inc., to oversee this study. BRC received consultation remuneration as a member of the Medical Advisory Board at Advance Health Solutions, LLC. He has also been an expert pulmonologist consultant for GlaxoSmithKline, Boehringer Ingelheim, Astra Zeneca, Novartis, and Pulmonix. ZX and TPG are employed by the University of California San Diego which received a grant from Advance Health Solutions, LLC, to implement this retrospective study. CD is employed by Sunovion Pharmaceuticals Inc. 


\section{References}

1. Centers for Disease Control and Prevention (CDC). Chronic Obstructive Pulmonary Disease. CDC website. https://www.cdc. gov/copd/index.html.

Updated June 2018. Accessed December 30, 2018.

2. Ford ES, Mannino DM, Giles WH, Wheaton AG, Liu Y, Croft JB. Prescription practices for chronic obstructive pulmonary disease: findings from the national ambulatory medical care survey 1999-2010. COPD. 2014;11(3):247-255. doi: https://doi.org/10.3109/15412555.2013.840570

3. American Lung Association (ALA). How Serious is COPD? COPD prevalence in adults by state, 2015. ALA website. http:// www.lung.org/lung-health-and-diseases/lung-disease-lookup/ copd/learn-about-copd/how-serious-is-copd.html.

Updated March 2018. Accessed December 29, 2018.

4. Ford ES, Murphy LB, Khaviou O, Giles WH, Croft JB. Total and state-specific medical and absenteeism costs of COPD among adults aged $\geq 18$ years in the United States for 2010 and projections through 2020. Chest. 2015;147(1):31-45.

doi: https://doi.org/10.1378/chest.14-0972

5. Jinjuvadia C, Jinjuvadia R, Mandapakala C, Durairajan N, Liangpunsakul S, Soubani AO. Trends in outcomes, financial burden, and mortality for acute exacerbation of chronic obstructive pulmonary disease (COPD) in the United States from 2002 to 2010. COPD. 2017;14(1):72-79.

doi: https://doi.org/10.1080/15412555.2016.1199669

6. Global Initiative for Chronic Obstructive Pulmonary Disease (GOLD). Global Strategy for the Diagnosis, Management, and Prevention of COPD. GOLD website. https://goldcopd.org/wpcontent/uploads/2017/11/GOLD-2018-v6.0-FINAL-revised-20Nov_WMS.pdf. Published 2018. Accessed December 19, 2018.

7. Beeh KM, Burgel PR, Franssen FME, et al. How do dual longacting bronchodilators prevent exacerbations of chronic obstructive pulmonary disease? Am J Respir Crit Care Med. 2017;196(2):139-149.

doi: https://doi.org/10.1164/rccm.201609-1794CI

8. Bateman ED, Mahler DA, Vogelmeier CF, Wedzicha JA, Patalano F, Banerji D. Recent advances in COPD disease management with fixed-dose long-acting combination therapies. Expert Rev Respir Med. 2014;8(3):357-379.

doi: https://doi.org/10.1586/17476348.2014.910457

9. Welsh EJ, Cates CJ, Poole P. Combination inhaled steroid and long-acting beta2-agonist versus tiotropium for chronic obstructive pulmonary disease. Cochrane Database Syst Rev. 2013;(5):CD007891.

doi: https://doi.org/10.1002/14651858.CD007891.pub3

10. Curtis JL, Martinez CH. Preventing COPD exacerbations: new options for a crucial and growing problem. Fed Pract. 2014;31(3):18S-24S.
11. Nishi SPE, Maslonka M, Zhang W, Kuo YF, Sharma G. Pattern and adherence to maintenance medication use in Medicare beneficiaries with chronic obstructive pulmonary disease: 20082013. Chronic Obstr Pulm Dis. 2018;5(1):16-26. doi: https://doi.org/10.15326/jcopdf.5.1.2017.0153

12. Chrystyn H, van der Palen J, Sharma R, et al. Device errors in asthma and COPD: systematic literature review and metaanalysis. NPJ Primary Care Respir Med. 2017;27(1):22. doi: https://doi.org/10.1038/s41533-017-0016-z

13. Yawn BP, Colice GL, Hodder R. Practical aspects of inhaler use in the management of chronic obstructive pulmonary disease in the primary care setting. Int $J$ Chron Obstruct Pulmon Dis. 2012;7:495-502. doi: https://doi.org/10.2147/COPD.S32674

14. Price D, Keininger DL, Viswanad B, Gasser M, Walda S, Gutzwiller FS. Factors associated with appropriate inhaler use in patients with COPD - lessons from the REAL survey. Int J Chron Obstruct Pulmon Dis. 2018;13:695-702. doi: https://doi.org/10.2147/COPD.S149404

15. Dhand R, Mahler DA, Carlin BW, et al. Results of a patient survey regarding COPD knowledge, treatment experiences, and practices with inhalation devices. Respir Care. 2018;63(7):833839. doi: https://doi.org/10.4187/respcare.05715

16. Pritchard JN. Industry guidance for the selection of a delivery system for the development of novel respiratory products. Expert Opin Drug Deliv. 2015;12(11):1755-1765. doi: https://doi.org/10.1517/17425247.2015.1056148

17. Centers for Medicare and Medicaid Services (CMS). Chronic conditions among Medicare beneficiaries, chartbook, 2012 Edition. Baltimore, MD. CMS website. https://www.cms.gov/ research-statistics-data-and-systems/statistics-trends-andreports/chronic-conditions/downloads/2012chartbook.pdf. Published 2012. Accessed November 5, 2018.

18. Wier LM, Elixhauser A, Pfuntner A, Au DH. Overview of hospitalizations among patients with COPD, 2008. Statistical Brief \#106. Rockville, MD: Agency for Healthcare Research and Quality website. https://www.hcup-us.ahrq.gov/reports/ statbriefs/sb 106.jsp.

Published February 2011. Accessed November 7, 2018.

19. Kronick R, Gilmer TP, Dreyfus T, Ganiats TG. CDPS-Medicare: The chronic illness and disability payment system modified to predict expenditures for Medicare beneficiaries. Final Report to CMS. CDPS website. http://cdps.ucsd.edu/CDPS_Medicare.pdf. Published June 2002. Accessed July 21, 2017.

20. Winnicka L, Molina J, Duran C, Subramanian CR. Improved COPD control with combination LABA/CS using small volume nebulized delivery. Chest. 2016;150(4):924A. doi: https://doi.org/10.1016/j.chest.2016.08.1024

21. Dhamane AD, Moretz C, Zhou Y, et al. COPD exacerbation frequency and its association with health care resource utilization and costs. Int J Chron Obstruct Pulmon Dis. 2015;10:2609-2618. doi: https://doi.org/10.2147/COPD.S90148 
22. Stuart BC, Simoni-Wastilla L, Zuckerman IH, et al. Impact of maintenance therapy on hospitalization and expenditures for Medicare beneficiaries with chronic obstructive pulmonary disease. Am J Geriatr Pharmacother. 2010;8(5):441-453. doi: https://doi.org/10.1016/j.amjopharm.2010.10.002

23. Cazzola M, Rogliani P, Matera MG. Escalation and de-escalation of therapy in COPD: myths, realities and perspectives. Drugs. 2015;75(14):1575-1585.

doi: https://doi.org/10.1007/s40265-015-0450-6

24. Wang Q, Bourbeau J. Outcomes and health-related quality of life following hospitalization for an acute exacerbation of COPD. Respirology. 2005;10(3):334-340. doi: https://doi.org/10.1111/j.1440-1843.2005.00718.x

25. Shah T, Press VG, Huisingh-Scheetz M, White SR. COPD readmissions: addressing COPD in the era of value-based health care. Chest. 2016;150(4):916-926.

doi: https://doi.org/10.1016/j.chest.2016.05.002

26. Feemster LC, Au DH. Penalizing hospitals for chronic obstructive pulmonary disease readmissions. Am J Respir Crit Care Med. 2014;189(6):634-639.

doi: https://doi.org/10.1164/rccm.201308-1541PP

27. Davis JR, Wu B, Kern DM, et al. Impact of nonadherence to inhaled corticosteroid/LABA therapy on COPD exacerbation rates and healthcare costs in a commercially insured US population. Am Health Drug Benefits. 2017;10(2):92-102.

28. Bender BG. Nonadherence in chronic obstructive pulmonary disease patients: What do we know and what should we do next? Curr Opin Pulm Med. 2014;20(2):132-137. doi: https://doi.org/10.1097/MCP.0000000000000027

29. Cecere LM, Slatore CG, Uman JE, et al. Adherence to long-acting inhaled therapies among patients with chronic obstructive pulmonary disease (COPD). COPD. 2012;9(3):251-258. doi: https://doi.org/10.3109/15412555.2011.650241

30. Koehorst-ter HK, Movig K, van der Valk P, van der Palen J, Brusse-Keizer M. The influence of type of inhalation device on adherence of COPD patients to inhaled medication. Expert Opin Drug Deliv. 2016;13(4):469-475.

doi: https://doi.org/10.1517/17425247.2016.1130695

31. Darbà J, Ramírez G, Sicras A, Francoli P, Torvinen S, Sánchezde la Rosa R. The importance of inhaler devices: the choice of inhaler device may lead to suboptimal adherence in COPD patients. Int Chronic Obstr Pulm Dis. 2015;10:2335-2345. doi: https://doi.org/10.2147/COPD.S90155

32. Braido F, Chrystyn H, Baiardini I, et al. Trying, but failing. The role of inhaler technique and mode of delivery in respiratory medication adherence. $J$ Allergy Clin Immunol Pract. 2016;4(5):823-832. doi: https://doi.org/10.1016/j.jaip.2016.03.002
33. Barrons R, Pegram A, Borries A. Inhaler device selection: special considerations in elderly patients with chronic obstructive pulmonary disease. Am J Health Syst Pharm. 2011;68(13):12211232. doi: https://doi.org/10.2146/ajhp100452

34. Barrons R, Wheeler J, Woods JA. Opportunities for inhaler device selection in elderly patients with asthma or COPD. Patient Intelligence. 2015;7:53-65. doi: https://doi.org/10.2147/PI.S61200

35. Molimard M, Raherison C, Lignot S, et al. Chronic obstructive pulmonary disease exacerbation and inhaler device handling: real-life assessment of 2935 patients. Eur Respir J. 2017;49(2):1601794.

doi: https://doi.org/10.1183/13993003.01794-2016

36. Kaplan A, Price D. Matching inhaler devices with patients: the role of the primary care physician. Can Respir J. 2018;2018:9473051. doi: https://doi.org/10.1155/2018/9473051

37. Usmani OS, Lavorini F, Marshall J, et al. Critical inhaler errors in asthma and COPD: a systematic review of impact on health outcomes. Respir Res. 2018:19(1):10. doi: https://doi.org/10.1186/s12931-017-0710-y

38. Chrystyn H, Small M, Milligan G, Higgins V, Gil EG, Estruch J. Impact of patients' satisfaction with their inhalers on treatment compliance and health status in COPD. Respir Med. 2014;108(2):358-365.

doi: https://doi.org/10.1016/j.rmed.2013.09.021

39. Sharafkhaneh A, Wolf RA, Goodnight S, Hananua NA, Make BJ, Tashkin DP. Perceptions and attitudes toward the use of nebulized therapy for COPD: patient and caregiver perspectives. COPD. 2013;10(4):482-492.

doi: https://doi.org/10.3109/15412555.2013.773302

40. Katajisto M, Koskela J, Lindqvist A, Kilpelainen M, Laitinen T. Physical activity in COPD patients decreases short-acting bronchodilator use and the number of exacerbations. Respir Med. 2015; 109(10): 1320-1325. doi: https://doi.org/10.1016/j.rmed.2015.08.001 